\title{
Changing The Culture Of A School: The Effect Of Larger Class Size On Instructor And Student Performance
}

\author{
Faruk Guder, Loyola University Chicago, USA \\ Mary Malliaris, Loyola University Chicago, USA \\ Anahita Jalilvand, Loyola University Chicago, USA
}

\begin{abstract}
Over time, each school builds its own culture and approach to education. Students, faculty, and alumni become accustomed to the style and pace of their university setting and expect it to continue. Thus, deliberate changes to this culture are not undertaken lightly and the effects of such changes are watched closely. This paper discusses the process and results of a change initiated by the School of Business Administration (SBA) at Loyola University Chicago. The change involved the increase of the maximum class size on the undergraduate level. In the fall of 2006, it was increased by 50 percent. The effect of this change was tracked in two ways: both student results, as measured by the grade point average, and faculty results, as measured by instructor evaluations, were collected and are reported here for a period of three years. This study uses data collected over the three years and includes results from 833 sections representing 23,247 student evaluations. For all terms in this period, data from the traditional and larger sized classes were compared and no significant difference was found either in instructor or student performance.
\end{abstract}

Keywords: large classes, instructor evaluations, student performance, class size

\section{INTRODUCTION}

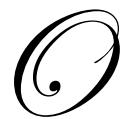

ne change that has greatly affected the teaching culture in universities is the rise of large class sizes. Pressure to increase the number of students enrolled in a class comes from both external and internal sources. Externally, the increasing number of high school graduates, along with the increasing demand from students to become business majors, has resulted in larger student bodies within business schools. In an effort to satisfy these student demands and limit expenses, university administrators seek to increase faculty teaching loads. Research faculty members, however, request smaller course loads to accommodate their research interests, as publications are an important part of the tenure and promotion process.

The effect of class size on scholastic achievement and on instructor ratings has been studied in depth by numerous authors. Levin (2001) and Hanushek (1986) found it to be insignificant. Feldman (2007) and Aleamoni (1987) report that student ratings may be slightly higher for smaller classes, as do Arias and Walker (2004). Kamuche (2006) studied very small classes of less than 20 and found a positive relationship between size and grades. Vreven and McFadden (2007) found that a large class size does not negatively affect student learning. Centra (2003) found that student evaluations are more affected by the course being at the right level of difficulty. Maasoumi et al (2005) discovered class size had a non-uniform impact on ratings. Driscoll et al (2005) report studies with widely differing conclusions: some indicate class size has a positive impact, some a negative impact, and some indicate no correlation at all. Centra and Gaubatz (2000) found that class size affects evaluations only when the class size is under 15 students. In contrast, McPherson (2006), in a study of 607 economics classes, found that class size is a significant determinant in student evaluations. Mukherji (2006) also found small class size to 
have a positive relationship to the instructor evaluation. Thus, the findings about the overall effect of a larger class size vary from study to study.

In addition to the non-conclusive nature of the literature, the external and internal demands faced by universities today are equally at odds. Students and administrators want more seats available while faculty want to teach fewer classes to free up time for research demands. However, universities have been able to respond satisfactorily to all stakeholders because of the advent of two important changes: clinical faculty and technology. Non-tenured, nontenure-eligible faculty, often designated as clinical faculty, with industry expertise and no research expectations, have become an important resource for instruction. They are able to devote all their university time to teaching and student involvement. This means that they can teach more classes than a standard tenure-track faculty with high research expectations is able to do. Technology has enabled faculty to make information available to students in a way that today's students prefer. It also allows faculty to interact easily with a larger number of students in an on-demand way via e-mail and systems such as Blackboard. Thus, personal interaction between faculty and students is supported even with larger numbers of students in the classes.

Up until the Fall semester of 2006, the SBA undergraduate classes had caps ranging from 10 to 40 students per class, although occasionally a few more students who needed a class caused this cap to expand by 3 or 4 . In other words, the largest classes enrolled up to 44 students, while others enrolled anywhere within the given range. Classes of these sizes meant that faculty knew the students and had enough time to respond to each student's comments and concerns. This was a style of teaching that faculty and students had come to expect from their business classes. Because of the internal and external factors mentioned earlier, however, the SBA, after much discussion, decided to increase the upper limit on class sizes by 50\%. This increased the range of caps set on classes from 10-40 to 10-60; some classes that previously only accepted 40 students could now enroll up to 60 students, while the smallest class size maintained its 10 student requirement. For the SBA, large classes were designated as those that enrolled 50 or more students.

For those universities where classes of hundreds are common, a class of 60 might seem small. But for the SBA, with faculty and students accustomed to an average of 25 students per class, increasing the class size by $50 \%$ meant many adjustments. Many were concerned that the students would have less opportunity for class discussion and direct contact with a faculty person. For faculty, it meant more papers per class and more names to learn. In addition, classroom dynamics change with increasing class sizes, and in order to accommodate this, faculty had to change their teaching style. There were also benefits: the increased availability of classes allowed more students to become business majors. The university was able to admit more students. For faculty members, while the total number of students they taught stayed the same, research faculty could teach fewer sections. That is, a research active faculty could decrease the number of sections he or she taught by one or two per year.

The remainder of this paper details the process and results of our change to larger classes. Specifically, we discuss the process for and results from the decision to increase class size by 50 percent. The next section covers the preparations necessary for the switch to larger classes. After a discussion of the process, we describe the data sets used. Two sections follow with detailed results of the impact on both students and faculty. Last, a conclusion section summarizes our experiences with the move to larger classes and its impact on our teaching culture.

\section{PREPARATION FOR THE CLASS CHANGE}

When the SBA made the decision to consider an increase in class size, meetings were held with faculty where the pros and cons of the possible change were discussed at length. Once faculty and administrators had agreed on the concept, a large effort was expended to ensure that the transition went as smoothly as possible. Possible points of difficulty were identified; for example, the lack of knowledge about the Blackboard system for communicating with students, the possible difficulty in meeting student demands for individual attention, such as tutoring during office hours, the longer time needed for grading the additional $50 \%$ of papers, and an equitable workload policy. These issues were brought up as key concerns and discussed in depth.

At the time, not all faculty were familiar with using a class management system such as Blackboard. Training classes were made available and faculty who were more adept in using the system volunteered to meet one- 
on-one with non-users to train them. The Blackboard system has turned out to be very popular among both faculty and students. Materials for the class are posted and can be accessed at any time through the internet. Faculty can post announcements, and homework can be assigned, submitted, and graded in the Blackboard environment. Students are not limited to waiting for office hours in order to access information or find out how they did on an assignment. For help with individual tutoring, faculty were allowed to hire student workers to hold scheduled tutoring times for other students. Student workers were also made available to help instructors in the areas not involving course grading.

Clinical faculty were hired in areas with the greatest demand from students for more classes, which were typically core classes. Clinical faculty taught a larger number of the large sized classes. This allowed the administration to give lower loads to research active faculty. The workload policy was developed by the school advisory board after much faculty discussion.

The last step in the move to larger class sizes was in the decision on how the SBA would measure the results and determine the success of the move. We chose two measures, one involving student performance and the other involving faculty performance. Grade point average was used to assess student performance, and instructor ratings were used to gauge faculty performance.

\section{DATA}

This study uses data collected over the three years 2006-07, 2007-08, and 2008-09. It includes results from 833 sections, including 23,247 student evaluations. Of these evaluations, 10,975 were from large classes and 12,272 were from small classes (See Table 1). The core courses had a larger portion of the larger classes. A small portion of advanced classes had large classes (See Table 2).

Table 1. Large and Small Classes

(Number, Evaluation and Enrollment)

\begin{tabular}{|l|c|c|c|}
\cline { 2 - 4 } \multicolumn{1}{c|}{} & Large & Small & Total \\
\hline Number of Sections & 298 & 535 & 833 \\
\hline Number of Evaluations & 10,975 & 12,272 & 23,247 \\
\hline Average Enrollment & 58 & 32 & -- \\
\hline
\end{tabular}

Table 2. Core, Advanced, Large and Small Classes (Number, Evaluation and Enrollment)

\begin{tabular}{|l|c|c|c|c|}
\cline { 2 - 5 } \multicolumn{4}{c|}{} & \multicolumn{3}{c|}{ (Number, Evaluation and Enrollment) } \\
\cline { 2 - 5 } \multicolumn{1}{c|}{} & Large & Small & Large & Small \\
\hline Number of Sections & 234 & 227 & 64 & 308 \\
\hline Number of evaluations & 8,840 & 5,672 & 2,135 & 6,600 \\
\hline Average Enrollment & 59 & 37 & 55 & 31 \\
\hline
\end{tabular}

The evaluations were collected at the end of the term and were anonymous. Faculty members were not involved in the distribution or collection of evaluations and were notified of their results only after all grades had been submitted. The faculty includes full-time tenure track, clinical, and part-time teachers. The student population represents all four years of the undergraduate spectrum. The departments in the SBA include Accounting (ACCT), Economics (ECON), Finance (FINC), Human Resources and Employment Relations (HRER), Information Systems and Operations Management (ISOM), Management (MGMT), and Marketing (MARK).

The student evaluation of teaching performance is a 20 question Likert-type scale with answers ranging from 1 (lowest) to 5 (highest) on each question. One of the questions (question 19) asks students to rank the overall quality of the instructor. This is the question used reported in this study. All instructor evaluations for a specific section of a class were averaged to generate a single score for the instructor of that section. In addition to the instructor rating for each section taught, the data set includes the department to which the class belongs, the type of 
instructor (tenure track, clinical, or part-time), whether the class is in the required core or is an optional advanced class, the number of enrolled students, and the number of evaluations submitted for that section. The student performance was gauged by the grades they received in a given course/section; letter grades were converted into numbers based on a 4-point scale. The average GPA calculated for each class was then used to compare the students' performances in large and small classes.

\section{RESULTS: EVALUATION OF THE INSTRUCTOR}

The instructor performance in large classes was compared to the performance in small classes. Therefore, the difference in ratings for small and large classes in the following tables is calculated as the average over all large classes minus the average over all small classes. Thus, positive differences indicate that the large class average was higher while negative numbers indicate that the small class average was higher. The difference in average instructor ratings is shown in Table 3. Although small classes have a slightly larger average, the numbers for the two types of classes are not significantly different at the 0.05 level.

Table 3. Difference in Average Instructor Ratings

\begin{tabular}{|c|c|}
\hline & Difference \\
\hline Instructor Rating & -0.087 \\
\hline
\end{tabular}

When separated into core and advanced classes, we see in Table 4 that core classes do slightly better in the large sections, while advanced classes are slightly better in small sections.

Table 4. Core versus Advanced Class Instructor Ratings

\begin{tabular}{|c|c|}
\hline Class Level & Difference \\
\hline Core & 0.037 \\
\hline Advanced & -0.117 \\
\hline
\end{tabular}

Table 5 gives us a picture of the ratings for each type of faculty, which includes tenure-track, clinical, and part-time. The results here are mixed. Although all the differences are small, we see that the clinical faculty performed slightly better in large classes, the tenure-track faculty did somewhat better in small classes, and the parttime faculty had slightly better ratings in small classes.

Table 5. Instructor Ratings per Type of Faculty

\begin{tabular}{|c|c|}
\hline Faculty Type & Difference \\
\hline Clinical Faculty & 0.004 \\
\hline Tenure-Track Faculty & -0.145 \\
\hline Part-Time Faculty & -0.014 \\
\hline
\end{tabular}

Lastly, Table 6 shows the results for each department in the SBA. The instructor performance differences are given for core and advanced classes. Here, the results are also mixed, but they are not significantly different. ACCT, ISOM and MGMT have slightly larger scores for large sections in core classes, while ECON, FINC and MARK have slightly better instructor scores for small sections in core classes. The results for advanced classes are also mixed. Since all classes taught by the HRER department fall into the small class category, there is no difference to report for them. The ISOM department did not have any large advanced classes to compare against the small classes.

Table 6. Instructor Ratings per Department

\begin{tabular}{|l|l|l|}
\hline Department & $\begin{array}{l}\text { Difference } \\
\text { (Core) }\end{array}$ & $\begin{array}{l}\text { Difference } \\
\text { (Advanced) }\end{array}$ \\
\hline ACCT & 0.202 & 0.156 \\
\hline ECON & -0.198 & 0.249 \\
\hline FINC & -0.038 & -0.143 \\
\hline HRER & --- & --- \\
\hline ISOM & 0.264 & --- \\
\hline MARK & -0.143 & 0.067 \\
\hline MGMT & 0.037 & -0.055 \\
\hline
\end{tabular}


Thus, we see mixed results in Tables 3 through 6 . Sometimes larger class outperformed smaller classes in student instructor ratings, and sometimes smaller classes were rated more highly. Overall, the differences were not significant at the 0.05 significance level.

\section{RESULTS: AVERAGE STUDENT PERFORMANCE}

The difference in average GPA in large and small classes is shown in the table below (Table 7). Similar to the instructor performances above, the difference in GPAs for small and large classes in the following tables is calculated as the average GPA over all large classes minus the average GPA over all small classes. Thus, positive differences indicate that the large class GPA average was higher while negative numbers indicate that the small class GPA average was higher. Although the GPAs are comparable, the GPA in small classes is slightly higher than that in large classes, differing by 0.10 .

Table 7. Average Difference in GPA

\begin{tabular}{|c|c|}
\hline & Difference \\
\hline Average GPA & -0.100 \\
\hline
\end{tabular}

Table 8 compares the GPAs between large and small classes separated into the categories of core advanced sections. In this case, we also have mixed results as advanced courses show higher GPAs in small classes, while core courses show higher GPAs in large classes.

Table 8. Core versus Advanced Class, Average GPA

\begin{tabular}{|c|c|}
\hline Class Level & Difference \\
\hline Core & 0.03 \\
\hline Advanced & -0.12 \\
\hline
\end{tabular}

Next, GPA averages are compared based on type of faculty. The GPAs from courses taught by clinical, tenure-track, and part-time faculty are compared based on class size for core and advanced classes. Table 9 shows the results of this comparison, showing that smaller classes taught by the clinical faculty have somewhat higher student GPAs than large classes do. The student performance in classes taught by tenure-track and part-time faculty have mixed results.

Table 9. Average Difference in GPA by Type of Faculty

\begin{tabular}{|c|c|c|}
\hline Faculty Type & $\begin{array}{c}\text { Difference } \\
\text { (Core) }\end{array}$ & $\begin{array}{c}\text { Difference } \\
\text { (Advanced) }\end{array}$ \\
\hline Clinical Faculty & -0.274 & -0.106 \\
\hline Tenure-Track Faculty & 0.066 & -0.190 \\
\hline Part-Time Faculty & -0.005 & 0.076 \\
\hline
\end{tabular}

Table 10 compares the average GPAs based on class size and specific department for core and advanced classes separately. MGMT and MARK departments have the higher differences for core classes while ACCT, FINC and ISOM have negative differences in core classes. In all cases, the differences are not significant.

Table 10. Average GPA Difference by Department

\begin{tabular}{|c|c|c|}
\hline Department & $\begin{array}{c}\text { Difference } \\
\text { (Core) }\end{array}$ & $\begin{array}{c}\text { Difference } \\
\text { (Advanced) }\end{array}$ \\
\hline ACCT & -0.068 & 0.250 \\
\hline ECON & 0.000 & 0.095 \\
\hline FINC & -0.038 & -0.036 \\
\hline RER & --- & --- \\
\hline ISOM & -0.160 & --- \\
\hline MARK & 0.260 & 0.138 \\
\hline MGMT & 0.004 & 0.162 \\
\hline
\end{tabular}


Looking at the GPA results in the various breakdowns, we see that the student performance differences vary for large and small classes in these comparisons, though the difference is not statistically significant. This is an important endorsement for the success of large classes.

\section{CONCLUSIONS}

The transition to larger class sizes for the SBA has been a successful experiment. Through better and greater use of technology and training of faculty, increasing the class size has not been detrimental to either faculty or students. Several factors were important in our transition included faculty buy-in, availability of talented clinical faculty, and a class management system (Blackboard) that can be accessed anywhere and anytime by both faculty and students. The successful transition also required a change of teaching style and additional resources for help in tutoring and homework assessment.

We looked at a three-year spectrum of classes encompassing all 4 years of the undergraduate experience in order to evaluate the effect of increasing the class size by $50 \%$. There was no significant difference in the performance of large and small classes, whether from the standpoint of the instructor, as measured by student evaluations, or from that of the student, as measured by the class GPA. Thus, with careful preparation for the change in our culture of teaching, neither faculty nor students were adversely affected by the increase in the maximum class size.

We will continue to use larger classes as a vehicle to accommodate the increasing demand from students, who want greater access to the business curriculum, from faculty, who seek support in their research agendas, and from upper administration, who want to contain costs.

\section{AUTHOR INFORMATION}

Faruk Guder is Associate Dean and professor of Operations Management in the School of Business Administration at Loyola University Chicago. He teaches courses in the areas of operations management, quality management, and statistics. His research interests are in the areas of quality management, inventory management, and distribution facilities location in a price-responsive environment.

Mary Malliaris is an Associate Professor of Information Systems \& Operations Management in the School of Business Administration at Loyola University Chicago. She teaches courses in the area of data analysis including data mining, informatics, financial modeling, and statistics. She has research interests in several areas including applications of neural networks, modeling financial markets, hospital professional practice environments and gender in IT.

Anahita Jalilvand is a pre-medical student at Loyola University Chicago, studying Biochemistry and French. She is part of the Honor's College and has conducted research at Stritch Medical School examining the effects of anesthetics on neurogenesis. She has been a student scholar at the School of Business Administration for approximately a year.

\section{REFERENCES}

1. Aleamoni, L. M., Student Rating Myths versus Research Facts, Journal of Personnel Evaluation in Education, Vol 1, pp. 111-119, 1987.

2. Arias, J and D. Walker, Additional Evidence on the Relationship between Class Size and Student Performance, The Journal of Economic Education, Vol. 35, No. 4, pp. 311-329, Fall 2004.

3. Centra, J., Will Teacher Receive Higher Student Evaluations by Giving Higher Grades or Less Course Work?, Research in Higher Education, Vol. 44, No. 5, pp 495-518, October 2003.

4. Centra, John A. and Noreen B. Gaubatz, Is There Gender Bias in Student Evaluations of Teaching?, The Journal of Higher Education, Vol. 71, No. 1, pp. 17-33, Jan-Feb. 2000. 
5. Driscoll, D. P., Lazarony, J. Arney, and E. Weiss, Student Performance In Upper-Division Business Core Courses: Using Control Variables To Determine the Effect of Class Size, Journal of Business \& Economics Research, Vol. 3, No. 17, pp. 7-24, January 2005.

6. Feldman, K., Identifying Exemplary Teachers and Teaching: Evidence from Student Ratings, in R.P. Perry and J.C. Smart (eds.), The Scholarship of Teaching and Learning in Higher Education: An Evidence-Based Perspective, pp. 93-143, Springer, 2007.

7. Hanushek, E., The Economics of Schooling: Production and Efficiency in Public Schools, Journal of Economic Literature, Vol. 24, pp. 1141-1177, 1986.

8. Kamuche, F., Does Smaller Class Size Affect Student's Performance In Basic Statistics Class? An Empirical Study, International Business \& Economics Research Journal, Vol. 5, No. 8, pp. 39-44August 2006.

9. Levin, J., For Whom the Reductions Count: A Quantile Regression Analysis of Class Size and Peer Effects on Scholastic Achievement, Empirical Economics, Vol. 26, No. 1, pp. 221-246, March 2001.

10. Maasoumi, E., D. Millimet, and V. Rangaprasad, Class Size and Educational Policy: Who Benefits from Smaller Classes?, Econometric Reviews, Vol. 24, Issue 4, pp. 1532-4168, pp. 333 - 368, 2005.

11. McPherson, M., Determinants of How Students Evaluate Teachers, The Journal of Economic Education, Vol. 37, No. 1, pp. 3-20, Winter 2006.

12. Mukherji, S., Explanatory Factors For Overall Instructor and Course Ratings, Journal of College Teaching \& Learning, Vol. 3, No. 2, pp. 29-38, February 2006.

13. Vreven, D, and S. McFadden, An Empirical Assessment of Cooperative Groups in Large, TimeCompressed, Introductory Courses, Innovations in Higher Education, Vol. 32, pp. 85-92, 2007. 
NOTES 